\title{
C) Hitstótórica
}

Radiofonia espírita na cidade do Rio de Janeiro: organização,

financiamento e objetivos

\section{Spiritist radio broadcasting in the city of Rio de Janeiro: organization, financing, and objectives}

\section{Marco Aurélio Gomes de Oliveira}

Resumo: O presente artigo aborda um aspecto pouco conhecido da história da radiofonia brasileira: o investimento que alguns adeptos do Espiritismo, ligados à imprensa doutrinária e às entidades federativas, fizeram na radiofonia. Nele são recuperados os programas levados ao ar, seus responsáveis e aqueles que prestaram apoio moral e material. Também são analisados seus objetivos e expectativas quanto à utilização do rádio enquanto ferramenta de divulgação dos seus pontos de vista doutrinários. Além disso, são estudadas as estratégias de financiamento que os responsáveis pelos programas radiofônicos lançaram mão.

Palavras-chave: Espíritas; Radiofonia; Propaganda; Rio de Janeiro.

Abstract: This article discusses a little-known aspect of the history of Brazilian radio broadcasting: the investment that some followers of Spiritism, linked to the doctrinal press and federative entities, have made in radio broadcasting. It retrieves programs aired, those responsible for them and those who provided moral and material support. Their objectives and expectations regarding the use of the radio as a tool to disseminate their doctrinal points of view are also analyzed. In addition, the financing strategies that those responsible for radio programs have used are studied.

Keywords: Spiritists; Radio; Advertising; Rio de Janeiro.

Os espíritas da cidade do Rio de Janeiro, que já dispunham, desde I880, das páginas dos jornais diários e de seus próprios periódicos para divulgarem seus pontos de vista sobre a Doutrina Espírita, as mensagens mediúnicas que recebiam, suas polêmicas com outros espíritas ou com outras religiões e suas análises sobre a sociedade, passaram a contar também, a partir da década de I930, com o rádio para alcançarem seus companheiros de

\footnotetext{
"Bacharel e Licenciado em História pela UFF (Universidade Federal Fluminense) em 20Io. Mestre em História Social pela UFF (Universidade Federal Fluminense) em 2014.
} 


\section{C) Gitcastórica}

crença e o grande público. Os homens de carne, osso e Espírito começaram a veicular, através das invisíveis ondas hertz, suas visões de mundo e opiniões sobre o Espiritismo, a doutrina dos invisíveis.

A primeira iniciativa espírita que identifiquei no rádio foi através das páginas do jornal A Batalha que, na sexta-feira 25 de setembro de I93I, noticiou na programação da Rádio Educadora do Brasil a palestra do advogado Henrique de Andrade, que teria início às I8h45 indo até às I9 horas ${ }^{\mathrm{I}}$. "Os que quizerem ouvil-o nada mais terão a fazer que se approximarem, naquellas horas, dos apparelhos de radio proprios ou das vizinhanças." ${ }^{2}$ Aos que não possuíam aparelhos de rádio, a alternativa de escutarem o programa na casa de outras pessoas. Isso se deu nove anos depois das primeiras experiências de transmissões radiofônicas no Brasil, ocorridas durante a Exposição Internacional de 1922 (COELHO, 2OI4, p. 24). Neste mesmo dia, verifiquei que a maior parte da programação da rádio, iniciada às I4 horas, era composta por discos de músicas havendo, além da palestra espírita, uma aula de inglês e uma apresentação da Orquestra da própria emissora. Dias depois, em 30 de setembro, ainda pelo mencionado periódico, na coluna "Notas Espíritas", lemos que a Liga Espírita do Brasil contaria com aquele espaço na grade de programação da rádio nas sextasfeiras³. A Revista Espírita do Brasil de Novembro de 193I, órgão de divulgação da Liga Espírita do Brasil, informa que Henrique de Andrade, palestrante e membro desta entidade federativa, estava encarregado destas palestras 4 . A Liga Espírita do Brasil, portanto, abriu caminho e foi a pioneira na radiofonia espírita brasileira.

Henrique Andrade não foi o único espírita que usou o microfone da Rádio Educadora do Brasil. Na Revista Espírita do Brasil de dezembro de I93I, na seção "Casa dos Espíritas", podemos ler que "as palestras, no mês que findou, foram realizadas pelo Dr. Henrique de Andrade e pelo comandante João Torres"5, que era, naquele momento, presidente da Liga Espírita do Brasil e diretor da revista da entidade federativa. Sua presença não deve ter sido esporádica, uma vez que o jornal Mundo Espírita, em 4 de abril de 1932, noticiou sua participação ao lado de Henrique Andrade nestas palestras radiofonizadas. ${ }^{6}$ Entretanto, através da leitura da coluna espírita do jornal A Batalha, bem como da coluna "Broadcasting",

\footnotetext{
I "Rádio Educadora do Brasil". A Batalha. Rio de Janeiro, 25 de setembro de I93I, p. 4.

2 "Notas Espíritas". A Batalha. Rio de Janeiro, 23 de outubro de I93I, p. 4.

3 "Notas Espíritas". A Batalha, Rio de Janeiro, 30 de setembro de I93I, p. 5.

4 "O Espiritismo e o rádio". Revista Espírita do Brasil, Rio de Janeiro, novembro de I93I, p. 620.

5 "Palestras no rádio". Revista Espírita do Brasil, Rio de Janeiro, dezembro de I93I, p. 6I9.

6 "O Espiritismo e o Rádio". Mundo Espírita. Rio de Janeiro, 4 de abril de 1932. Citado por MONTEIRO, Eduardo Carvalho. História da radiodifusão espírita. São Paulo: Madras, 2004, p. 44.
} 


\section{C) GitisaróríRICA}

onde eram anunciadas as programações das emissoras de rádio, verifiquei que é Henrique Andrade quem aparece de maneira constante à frente do microfone da emissora de rádio. João Torres figurou na programação da mesma emissora, sozinho, durante os dias 3, 8 e 24 de agosto de 1933 para fazer palestra com o tema "Instrução e Educação"7. Dois meses depois, foi a vez da Federação Espírita Brasileira. Em 3 de outubro de 1933, no programa da rádio, consta uma transmissão de uma solenidade em homenagem a Allan Kardec, cujo nascimento se comemora nesta data $^{8}$. O texto sugere que a transmissão ocorreria a partir da sede da entidade federativa. Entretanto, nem o Reformador de $\mathrm{I}^{\mathrm{o}}$ de novembro de 1933 , revista da Federação Espírita Brasileira, nem a Revista Espírita do Brasil, da Liga Espírita do Brasil, que se fez representada por Henrique Andrade no evento, noticiaram a transmissão. Pode ser que ela não tenha ocorrido. Almerindo Martins de Castro ocupou também os microfones da Rádio Educadora do Brasil de I4 de junho até I9 de julho de 1932 para apresentar palestras, num total de quatro programas levados ao ar às terças-feiras por quinze minutos. Na grade de programação da emissora não consta que se tratava de palestras espíritas, trazendo apenas os temas. Reformador noticiou o programa em seu número de I6 de julho de I932, às vésperas do final das apresentações. A Federação Espírita Brasileira sugere que a iniciativa do programa partira da própria emissora de rádio, que teria escolhido Almerindo para leválo ao ar. ${ }^{9}$ Julgaram que o espaço aberto nesta emissora seria permanente, o que não ocorreu.

A Revista Espírita do Brasil, em junho de 1933, informa que os espíritas conseguiram, em maio de 1933, uma hora espírita na Sociedade Rádio Leopoldinense, que funcionava no bairro de Ramos. A iniciativa teria partido do médico Sylvio e Silva e de João Baptista Ribeiro Espíndola, apresentados pela revista como confrades. O secretário da rádio, cujo nome não foi mencionado, ficaria encarregado de fazer os convites aos palestrantes. Foi a única referência que encontrei sobre essa emissora de rádio nos periódicos ${ }^{10}$. Em todo caso, a própria emissora não teve vida longa. Em I6 de agosto de 1933, no Diário Oficial da União, os mesmos que se propunham abrir os microfones da emissora para os espíritas tiveram o "pedido de licença especial para o funcionamento de uma estação de rádio-difusão, em caráter experimental"II indeferido. Teria funcionado por um tempo sem registro legal? Não

\footnotetext{
7 "Rádio Educadora do Brasil". A Batalha, Rio de Janeiro, 24 de agosto de 1933, p. 4.

8 "Rádio Educadora do Brasil". A Batalha, Rio de Janeiro, 3 de outubro de I933, p. 5.

9 "Propaganda Radiophonica". Reformador. Rio de Janeiro, I6 de julho de 1932, p. 397. Sobre Almerindo Martins de Castro, ver: “Almerindo Martins de Castro". Disponível em: https://www.febnet.org.br/wpcontent/uploads/20I2/o6/Almerindo-Martins-de-Castro.pdf Último acesso em 3I de maio de 2020.

Io "O rádio e o Espiritismo". Revista Espírita do Brasil, Rio de Janeiro, junho de I933, p. I04 e I05.

II "Requerimentos despachados”. Diário Oficial da União, I6 de agosto de I933, seção I, p. I620I.
} 


\section{C) Gitcastórica}

é possível dizer se algum programa foi levado ao ar. Se o foi, não repercutiram na imprensa doutrinária.

Poucos anos depois, em I9 de agosto de I937, numa quinta-feira às 20 horas, tem início o programa "Hora Espiritualista", sob a responsabilidade de João Pinto de Souza pela Rádio Sociedade Fluminense (PRE - 6), da cidade de Niterói ${ }^{12}$. Aqueles que não possuíssem aparelho de rádio estavam "convidados a comparecer ao studio". ${ }^{13}$ Tenente do Exército, presidente do Centro Espírita Fé e Caridade do bairro de Olaria ${ }^{14}$, responsável pela coluna espírita do jornal A Pátria e secretário da Liga Espírita do Brasil, além de ter participado de sua fundação, ${ }^{15}$ João Pinto de Souza compartilhou o microfone da rádio com outros companheiros de ideal espírita. Gerson Simões Monteiro, recordando os programas radiofônicos espíritas, assinala trinta e cinco nomes de participantes da "Hora Espiritualista", dos quais oito eram mulheres. Consegui localizar apenas um nome de espírita mais identificado com a Federação Espírita Brasileira, que era Carlos Imbassahy, secretário da revista Reformador (OLIVEIRA, 2015, p. 68). Vinculados à Liga Espírita do Brasil encontrei João Carlos Moreira Guimarães, que foi secretário da Revista Espírita do Brasil, Aurino Barbosa Souto, naquele momento vice-presidente da federativa, Alvaro Brandão da Rocha, então secretário da federativa e responsável pela coluna espírita no jornal Vanguarda, João Torres, presidente da Liga, Deolindo Amorim, procurador e Henrique Andrade, expresidente $^{16}$. Muitos destes espíritas, embora demonstrassem mais identificação e ocupassem cargos em determinados Centros Espíritas ou em certas entidades federativas e escrevessem para os periódicos destas, também mantinham vínculos com outros Centros e federativas, frequentando-lhes as atividades ou colaborando de alguma forma. Nem sempre restringiam, portanto, suas atividades a determinada instituição ${ }^{17}$. O critério que utilizei para

\footnotetext{
I2 "Inauguração da Hora Espírita". A Batalha. Rio de Janeiro, 2I de agosto de 1937, p. 5.

13 "Correio Espírita”. Correio da Manhã. Rio de Janeiro, 24 de agosto de 1937, p. 12.

I4 "Correio Espírita". Correio da Manhã. Rio de Janeiro, 25 de março de I937, p. I4.

I5 "Correio Espírita". Correio da Manhã. Rio de Janeiro, 3I de março de I937, p. 9. Sobre sua participação na fundação da Liga Espírita do Brasil, ver: “João Pinto de Souza”. Revista Espírita do Brasil. Rio de Janeiro, setembro de 1943, p. 3.

16 "As obras da caridade espírita". Correio da Manhã, Rio de Janeiro, I7 de junho de I937, Suplemento, p. I6. As mulheres citadas foram: Telma Campos Ávila de Souza, Acelina Póvoas, Celene Valadares, Altiva Duarte Monteiro, Jurema Póvoa, Hilda de Freitas, Marília Barbosa e Carmelita Brasil. MONTEIRO, Gerson Simões. "Programas espíritas radiofônicos". Correio Espírita. Disponível em: https://www.correioespirita.org.br/index.php?option=com_content\&view=article\&id=879:prog Último acesso em 26 de abril de 2020.

${ }^{17}$ A Revista Espírita do Brasil, da Liga Espírita do Brasil, no seu número de fevereiro de i934, publicou artigo de Carlos Imbassahy, secretário do Reformador, revista da Federação Espírita Brasileira. IMBASSAHY, Carlos. "Por que o reverendo não pode ser espírita". Revista Espírita do Brasil, Rio de Janeiro, fevereiro de 1934, p. 29. Henrique Andrade participa, por iniciativa própria, de comemoração do aniversário de Allan Kardec em 3 de outubro de 1933 realizada na Federação Espírita Brasileira, com espaço para discursar. "A segunda reunião do Conselho Federativo". Reformador, Rio de Janeiro, I de novembro de 1933, p. 565 a 568.
} 


\section{C) GitistóróRICA}

determinar uma ligação mais forte com alguma instituição foi a ocupação de cargos nela. Dados os vínculos institucionais entre o responsável pelo programa radiofônico e aqueles que participaram dos programas, não é de se espantar, portanto, que a presença de espíritas oriundos da Liga Espírita do Brasil seja predominante.

Analisando o extrato dos estatutos da "Hora Espiritualista", verifiquei que sua diretoria era composta por presidente, tesoureiro, secretário geral e subsecretário. Possuía um conselho fiscal composto por três membros, um conselho de cultura e orientação contando com duas pessoas e um conselho de propaganda e recepção composto por nove pessoas $^{18}$. Com a provável presidência de João Pinto de Souza, não consegui identificar os demais componentes desta diretoria.

Em 3 I de julho de 1943, com a morte de João Pinto de Souza, o programa ficou sob a responsabilidade de Geraldo de Aquino, que já participava dele ${ }^{19}$. Segundo Aurino Souto, comemorando pela Revista Espírita do Brasil o sexto aniversário do programa em 1943, esta seria a vontade do recém-falecido, "que fazia questão de vê-lo, do outro lado da vida, sucedendo-o neste mister." 20 De acordo com Gerson Simões Monteiro, no dia do sepultamento, o general Daniel Cristóvão sugeriu que o programa passasse a se chamar "Hora Espiritualista João Pinto de Souza", o que teria sido aceito por Geraldo de Aquino, sendo já no programa seguinte apresentado com este nome ${ }^{21}$. A retomada não foi tranquila. A Revista Espírita do Brasil de novembro de 1944 informa que o programa sofreu uma interrupção de alguns meses, que deve ter ocorrido em algum momento depois da comemoração do seu sexto aniversário em agosto de 1943, mas retomou suas atividades em 22 de outubro de 1944 novamente na Rádio Sociedade Fluminense. ${ }^{22}$ Em 30 de setembro de I95I, os estatutos são reformados apresentando o novo nome. Sua diretoria era composta por presidente, secretário geral, $\mathrm{I}^{\mathrm{o}}$ e $2^{\mathrm{o}}$ secretários, $\mathrm{I}^{\mathrm{o}}$ e $2^{\circ}$ tesoureiro e procurador. Seu Conselho fiscal era composto por três pessoas. A estrutura administrativa é, portanto, drasticamente reduzida, passando de dezoito pessoas, na época de João Pinto de Souza, para dez, na administração de Geraldo de Aquino, dada a extinção dos conselhos de cultura e orientação e o de propaganda e recepção ${ }^{23}$. Gerson Simões Monteiro diz ainda que Geraldo de Aquino

\footnotetext{
I8 “O Espiritismo pelo rádio". Diário da Noite. Rio de Janeiro, 7 de agosto de I939, p. I9.

19 SOUTO, Aurino Barbosa. "Saudação à Hora Espiritualistas" da Rádio Ipanema do Rio de Janeiro, pela passagem do seu 6º aniversário”. Revista Espírita do Brasil, Rio de Janeiro, setembro de I943, p. 2.

${ }^{20}$ Idem.

${ }^{21}$ MONTEIRO, Gerson Simões. "Programas espíritas radiofônicos”. Correio Espírita, op. cit.

${ }^{22}$ SOUTO, Aurino Barbosa. "Volta ao ar a Hora Espiritualista “João Pinto de Souza"”. Revista Espírita do Brasil. Rio de Janeiro, novembro de I944, p. I3.

23 "Hora Espiritualista João de Souza". Diário Oficial da União, I9 de novembro de I95I, p. I70I2.
} 


\section{C) Gitcastórica}

criou, em I ${ }^{\circ}$ de novembro de 1948, o programa "Meditação e Evocação da Ave Maria", "de transmissão diária, a partir das I7 horas e 55 minutos" 24 pela Rádio Clube Brasil. Na mesma emissora, criou e apresentou ainda o programa "Bezerra de Menezes" em I $^{\mathrm{o}}$ de agosto de 1954, transmitido às noites de domingo e em I9 de novembro do mesmo ano o programa "Luz na Penumbra", "com a apresentação de músicas clássicas e números de piano, declamação, bel-canto e apresentação de páginas em Esperanto"25. O "Programa João Pinto de Souza" (antigo "Hora Espiritualista João Pinto de Souza") e "Luz na Penumbra" seriam dos programas radiofônicos mais antigos no ar em 20II, quando Gerson Simões Monteiro escreveu sobre eles. O segundo ainda hoje está na grade de programação da Rádio Rio de Janeiro, emissora espírita cujo processo de aquisição foi conduzido por Geraldo de Aquino. ${ }^{26}$

Quase dois anos depois do surgimento programa de rádio encabeçado por João Pinto de Souza e que contou com a participação de vários espíritas vinculados à Liga Espírita do Brasil, em I de junho de 1939 tem início a "Hora Espírita Radiofônica" pelos microfones da Rádio Transmissora (PRE - 3), que transmitiria o programa todas as quintas-feiras, das I8 às I9 horas. À frente dele estaria uma comissão formada pelo professor Leopoldo Machado, presidente do Centro Espírita Fé, Esperança e Caridade de Nova Iguaçu, que colaborava com a revista Reformador, "Luiz Fernandes da Silva Quadros, comerciante nesta cidade e de ha longo tempo espírita militante e devotado à causa; Victor Torquato de Souza, secretário do Centro E. de Jacarepaguá; e Francisco V. da Rocha Garcia, tesoureiro da Federação.” 27 Não por acaso Leopoldo Machado encabeçou a relação, afinal já tinha alguma experiência no rádio porque já havia colaborado, de acordo com ele, por um breve período na "Hora Espiritualista" de João Pinto de Souza ${ }^{28}$. Além disso, seria também “o idealizador e realizador, ao lado de companheiros capazes e dedicadíssimos." ${ }^{29}$ Uma nota publicada no jornal Correio da Manhã em 30 de maio de 1939 informa os cargos ocupados pelos membros da comissão, respectivamente: diretor, vice-diretor, secretário e tesoureiro ${ }^{30}$.

O vínculo do novo programa radiofônico com a Federação Espírita Brasileira era evidente. Anunciada em maio de 1939 pelo seu órgão oficial, contava em sua comissão com

\footnotetext{
${ }^{24}$ MONTEIRO, Gerson Simões. "Programas espíritas radiofônicos”. Correio Espírita, op. cit.

${ }^{25}$ Idem.

${ }^{26}$ RÁDIO RIO DE JANEIRO. “Programação”. Disponível em: https://www.radioriodejaneiro.am.br/programa/ Último acesso em 3I de maio de 2020. Sobre a criação da emissora, ver: RÁDIO RIO DE JANEIRO. "História da Rádio". Disponível em: https://www.radioriodejaneiro.am.br/historia-da-radio/ Último acesso em 3I de maio de 2020.

27 “Hora Espírita Radiofônica”. Reformador. Rio de Janeiro, maio de I939, p. I5I e I52.

${ }^{28}$ MACHADO, Leopoldo. "Pinto de Souza". Revista Espírita do Brasil. Rio de Janeiro, setembro de I943, p. I2 e I3.

${ }^{29}$ MACHADO, Leopoldo. Pigmeus contra gigantes. Rio de Janeiro: Imp. Of. "Reformador", I940, p. 6.

30 "Hora Espírita Radiofônica". Correio da Manhã. Rio de Janeiro, 3I de maio de I939, p. 9.
} 


\section{C) GitisaróríRICA}

um quadro de sua diretoria e com um representante de um Centro Espírita adeso à federativa. Victor Torquato de Souza era o responsável pela correspondência do programa, que deveria ser endereçada à sede da Federação Espírita Brasileira, na Avenida Passos nº. 30, no Centro. Luiz Olímpio Guillon Ribeiro, presidente da federativa, em seu relatório de atividades apresentado à Assembleia Deliberativa em 1939 e publicado no Reformador de setembro do mesmo ano, assim se refere à "Hora Espírita Radiofônica":

Constituído, em boa parte, de elementos identificados com o programa da Federação e com a sua orientação, pertencendo mesmo alguns ao quadro dos que consagram muito de suas atividades ao serviço desta instituição, nada o grupo dos iniciadores resolveu em definitiva, quando o projeto ainda não passara do período de estudos preliminares, sem lhe solicitar o parecer, por intermédio da sua Diretoria que, assim, podemos dize-lo, teve positiva interferência na realização da ideia inicial. ${ }^{31}$

Assim, as decisões em torno do programa de rádio passaram pelos dirigentes da federativa e foram construídos com grande participação deles, o que foi facilitado pelo fato de se tratar de pessoas vinculadas e identificadas com as pautas da entidade. A Federação Espírita Brasileira não participou, apenas, da elaboração do programa. Também colaborou com o seu funcionamento decidindo o que iria ou não ao ar. Afinal, além da comissão diretora, contariam com uma "Comissão de exame dos programas, á qual incumbirá apreciar tudo o que se destine á irradiação e sem cuja aprovação nenhum trabalho será irradiado."32 Compunham essa comissão Moreira Guimarães, o presidente e o vice-presidente da Federação Espírita Brasileira.

Embora a "Hora Espírita Radiofônica" estivesse vinculada à Federação Espírita Brasileira, ele não estava fechado à participação de elementos externos a seus quadros. $\mathrm{O}$ programa inaugural contou, além das participações de Leopoldo Machado e Luiz Olímpio Guillon Ribeiro, presidente desta federativa, com Leôncio Correia, então presidente da Liga Espírita do Brasil; Henrique Andrade, representando a União Espírita Suburbana, que já estivera à frente da primeira iniciativa radiofônica espírita e que era ex-presidente da Liga Espírita do Brasil; Álvaro Brandão da Rocha, que também já passara pela "Hora Espiritualista”, já apresentado; Humberto de Aquino, secretário da Associação Obreiros do

\footnotetext{
${ }^{31}$ RIBEIRO, Luiz Olímpio Guillon. "Relatório apresentado, pelo seu presidente, à Assembléia Deliberativa, na reunião ordinária de 1939, sôbre os trabalhos da instituição e a gestão do seu patrimônio moral e material, durante o ano social de I de Julho de 1938 a 30 de Junho de I939". Reformador. Rio de Janeiro, Setembro I939, p. 30I. Grifos meus.

32 "Hora Espírita Radiofônica". Reformador. Rio de Janeiro, maio de I939, p. I52.
} 


\section{C) Gitiston'RICA}

Bem. ${ }^{33}$ Henrique Andrade, em seu livro A bem da verdade, recorda-se de sua passagem pelo programa. Segundo ele, recebeu de Leopoldo Machado o convite para ser um dos diretores da "Hora Espírita Radiofônica", porém recusara-o alegando carência de tempo. Diante da insistência de Leopoldo, aceitou tomar parte nas reuniões da diretoria do programa e nos microfones da rádio durante cerca de três anos ${ }^{34}$. Além dele, Moreira Guimarães, que foi secretário da Revista Espírita do Brasil, também aparece listado como um dos "principais factores da obra em apreço"35, já que ajudava a decidir o que iria ao ar.

Os espíritas perceberam o potencial do rádio para a difusão de sua doutrina e resolveram investir esforços nele. Através da radiofonia, poderiam reforçar a ideia, para o público leigo e para os adeptos da doutrina em geral, daquilo que consideravam o legítimo Espiritismo. Na coluna "Notas Espíritas" do jornal A Batalha de 30 de setembro de I93I, a Liga Espírita do Brasil, representada por Henrique Andrade nos microfones da Rádio Educadora do Brasil, afirmou que utilizaria as ondas hertz "para com mais largueza serem diffundidos os ensinamentos espíritas, na conformidade do curso popular de Espiritismo que se vem realizando na Casa dos Espíritas" ${ }^{36}$. Sendo de natureza "popular", a abordagem dos temas doutrinários seria básica e não aprofundada. Oferecido por esta federativa a diretores e representantes de Centros Espíritas, o curso popular de Espiritismo objetivava “o estabelecimento possível e necessário da unidade do estudo e da prática experimental do Espiritismo" 37 . Entendiam que a padronização de estudos e práticas doutrinárias, de acordo com os ensinamentos contidos nas obras de Allan Kardec distinguiria os Centros Espíritas adesos à Liga Espírita do Brasil daqueles que eram considerados, por outros espíritas e pelas autoridades policiais, como viciosos, de "baixo espiritismo", que seriam mais expostos à repressão policial. Não por acaso, esta federativa oferecia aos diretores das instituições a ela agregadas instruções para o funcionamento das sessões espíritas. Para seus dirigentes, "qualquer desvio nos methodos regulares dos estudos da doutrina e prática do Espiritismo, em torno da repressão do vício e máos costumes, poderão arrastar sérios incommodos e prejuizos moraes para os creditos e propagação dos principios doutrinarios." 38 Pensavam, certamente, no estardalhaço que alguns jornais diários e religiosos adeptos de outras denominações poderiam fazer com as notícias sobre a ação policial em Centros Espíritas -

\footnotetext{
33 “A Hora Espírita Radiofônica - sua inauguração”. Reformador. Rio de Janeiro, junho de I939, p. I6I.

34 ANDRADE, Henrique. "Explicação necessária”. A bem da verdade. Rio de Janeiro: Edição Própria. Composta e impressa na Gráfica Mundo Espírita S. A., I946, p. XIII e XIV.

35 "A Hora Espírita Radiofônica". Reformador. Rio de Janeiro, junho de I940, p. I46.

36 "Notas Espíritas". A Batalha. Rio de Janeiro, 30 de setembro de I93I, p. 5.

37 "Notas Espíritas". A Batalha. Rio de Janeiro, 30 de junho de I93I, p. 7.

38 "Notas Espíritas". A Batalha. Rio de Janeiro, 3 de julho de I93I, p. 5.
} 


\section{C) Hitcastórica}

na verdade, nem tão espíritas assim para eles - para prenderem médiuns. A Liga Espírita do Brasil, naquele momento, considerava legítima a atitude policial contra os Centros Espíritas que não observassem o estudo e o método que preconizavam, assumindo postura muitas vezes preconceituosa contra esses que não consideravam espíritas de verdade. Nem sempre, porém, a Polícia fazia essas distinções doutrinárias e algumas vezes reprimiu as atividades dos espíritas que se consideravam legítimos. ${ }^{39}$

A nossa polícia, na hora derradeira, também vem incentivando a sua acertada e útil aç̧ão no golpeamento de taes excrescencias, que por ahi em fóra praticam, acobertando-se com a bandeira do Espiritismo. Nestes últimos dias as nossas autoridades têm agido activamente, pondo á descoberto antros de vícios, de vadiagem e de explorações, tendo na sua fachada pomposos nomes de "centros espíritas", quando as suas praticas não passam de "trabalhos" nocivos, "despachos" porcos e outras bobagens que a moral manda que calemos. ${ }^{40}$

Embora lhes faltasse tolerância para com aqueles que, em suas práticas doutrinárias, misturavam elementos do catolicismo ou das religiões afro-brasileiras, tomadas como indicadores de exploração da credulidade alheia, os espíritas da Liga Espírita do Brasil reclamavam-na para si e ficavam muito satisfeitos em recebê-la. Entendiam que a Rádio Educadora do Brasil "tão gentilmente vem contribuindo sob o mais accentuado principio de tolerância para o disseminamento e propaganda dos fundamentos básicos da doutrina espírita."4I

A preocupação que as pessoas entendessem bem o Espiritismo a fim de que ele não fosse confundido com outras religiões (e suas práticas) e, por isso, fosse criticado, era o que objetivava a Federação Espírita Brasileira com o uso do rádio no início da década de 1930. Quando Almerindo Martins de Castro ocupou os microfones da Rádio Educadora do Brasil, a federativa afirmou que isso teria "a immensa vantagem de collocar o grande publico em condições de bem julgar de uma doutrina geralmente calumniada, quanto adulterada nos seus fundamentos e finalidades." ${ }^{22}$ Se a Doutrina Espírita, conforme ensinada pela

\footnotetext{
39 Sobre a repressão policial às atividades dos espíritas, ver: OLIVEIRA, Marco Aurélio Gomes. "Livres", porém perseguidos: O cotidiano das relações entre espíritas e a Polícia na cidade do Rio de Janeiro (I930-1950). Monografia de Conclusão do Curso de Graduação em História. UFF, Niterói, 20Io. Sobre as tensões em torno do que se publicava sobre os espíritas nos jornais diários, ver: OLIVEIRA, Marco Aurélio Gomes. Imprensa Espírita na cidade do Rio de Janeiro, op. cit.

40 "Pelo bom nome do Espiritismo". Revista Espírita do Brasil. Rio de Janeiro, abril de I93I, p. 42I.

$4 \mathrm{I}$ "Notas Espíritas". A Batalha. Rio de Janeiro, II de fevereiro de I932, p. 4.

42 "Propaganda Radiophonica". Reformador, op. cit.
} 


\section{C) GitistóróRICA}

federativa ou por representantes seus, fosse realmente compreendida pelo grande público, não seria mais condenada publicamente por terceiros, porque todos saberiam distingui-la de práticas ou ensinamentos que lhes seriam estranhos.

Em 1937, Henrique Andrade, em correspondência para Cairbar Schutel, mostrava-se entusiasmado com as possibilidades que a radiofonia em desenvolvimento oferecia à divulgação doutrinária. Afirmava que "o melhor meio de propaganda na hora agitada e rápida que vivemos é o que se faz atravéz do espaço, pelas irradiações radiophonicas." 43 Para que fosse eficiente essa propaganda ela deveria ser feita "selecionando, com critério e versando assuntos que possam interessar aos que não são espíritas, despertando-os para o conhecimento da doutrina." $44 \mathrm{O}$ foco, portanto, deveria ser atrair novos adeptos para o Espiritismo. E essa divulgação deveria ser feita por pessoas que bem conhecessem a doutrina, a fim de que tivessem discernimento e sensibilidade na seleção dos assuntos.

A “Hora Espiritualista” comandada por João Pinto de Souza inicialmente na Rádio Sociedade Fluminense foi recebida como uma "victoria alcançada em pról da doutrina espírita" 45 pelo editor da coluna espírita do jornal A Batalha. O tempo dos espíritas nos microfones do rádio foi ampliado. Antes conseguiam programas de quinze minutos. Também demonstrando apoio ao novo programa de rádio, o editor da coluna “"Correio" Espírita" do Correio da Manhã, afirmava "que a propaganda do Espiritismo pelo "ar" é a mais efficiente divulgação da nossa doutrina." ${ }^{46}$ Aderindo com empolgação e valorizando o que seria levado ao ar, a coluna "Espiritismo" do jornal A Nação declara que, no programa "falarão os mais consagrados oradores do movimento espírita do Brasil". ${ }^{47}$ Anunciando o programa de rádio nas páginas de sua revista poucos meses depois do início de suas atividades, a Liga Espírita do Brasil, consciente de que as ondas hertz podiam chegar longe, declara que "os serviços propagandistas doutrinários da Hora Espírita são os mais assignalados, quer pelo critério adoptado em suas irradiações, quer pela extensão, levando a toda parte do Brasil informes seguros e immediatos dos acontecimentos espíritas". ${ }^{8}$ O tempo mais estendido nos microfones permitia não apenas falar da doutrina, mas também dos

\footnotetext{
43 ANDRADE, Henrique. Correspondência de Henrique Andrade a Cairbar Schutel. Rio de Janeiro, io de maio de 1937. Citado por MONTEIRO, Eduardo Carvalho. História da Radiodifusão Espírita, op. cit., p. 65.

44 Idem.

45 "Pelo culto espírita". A Batalha. Rio de Janeiro, 2I de agosto de I937, p. 5.

46 "”Correio" Espírita. Correio da Manhã. Rio de Janeiro, 25 de dezembro de I937, p. I4.

47 "Espiritismo". A Nação. Rio de Janeiro, 25 de julho de I937, p. 6.

48 "Hora Espírita". Revista Espírita do Brasil. Rio de Janeiro, janeiro de 1938, p. I9 e 20.
} 


\section{C) GitisaróríRICA}

espíritas e das atividades que desenvolviam. Embora se refira ao programa como "Hora Espírita", tratava-se da "Hora Espiritualista”.

De acordo com seus estatutos, publicados no Diário Oficial da União em I $^{\mathbf{0}}$ de agosto de 1939, o programa "tem por fim único a diffusão da doutrina do Espiritismo, sob o tríplice aspecto: religioso, philosophico e scientifico, por meio de estações emissoras de radio." 49 Os espíritas, que àquela altura já contavam com as páginas de alguns diários da cidade para a propaganda doutrinária, bem como de suas atividades, e num momento que viam o número de Centros Espíritas e adeptos crescerem, entenderam que suas capacidades de difusão da doutrina foram potencializadas com o rádio (OLIVEIRA, 20I5, p. 195). As ondas hertz poderiam levar os conhecimentos espíritas com velocidade às localidades mais distantes no país. De acordo com Lia Azevedo, “o rádio do final da década de 1930 era visto como um meio de comunicação fundamental e indispensável, só ele poderia informar, transmitir as notícias com a velocidade necessária dos novos tempos" (AZEVEDO, 2002, p. 68). Os organizadores do programa, ao menos como carta de intenções estatutária, registraram que o Espiritismo seria analisado nos seus três aspectos, não priorizando nenhum deles. De acordo com Allan Kardec, o Espiritismo seria, “ao mesmo tempo, uma ciência de observação e uma doutrina filosófica. Como ciência prática ele consiste nas relações que se estabelecem entre nós e os Espíritos; como filosofia, compreende todas as consequências morais que dimanam dessas mesmas relações." 50 Embora alguns espíritas negassem o caráter religioso do Espiritismo, outros o viveram como religião, inclusive aqueles ligados às duas entidades federativas (OLIVEIRA, 20I5, p. II3-II4). Contemplando os três aspectos, objetivavam alcançar todas as preferências, ainda que possam ter enfatizado alguma delas.

Saudada por alguns espíritas com inserção na imprensa diária, sendo comandada por um destes que, além de tudo, detinha responsabilidades numa federativa - a Liga Espírita do Brasil - e declarando, em seus estatutos, seu propósito espírita, a "Hora Espiritualista" parecia querer alcançar um público mais abrangente. João Pinto de Souza, que além disso era presidente de Centro Espírita, devia conhecer O livro dos Espíritos, de Allan Kardec. O autor francês, que apresenta esta obra como "Filosofia espiritualista", no item I de sua introdução discute o uso das palavras "espiritualismo", "espiritualista", "espiritismo" e "espírita". De acordo com ele, "quem quer que acredite haver em si alguma coisa mais do que matéria, é espiritualista. Não se segue, daí, porém, que creia na existência dos Espíritos

49 "O Espiritismo pelo rádio". Diário da Noite, op. cit..

$5^{\circ}$ KARDEC, Allan. O que é o Espiritismo. Rio de Janeiro: FEB, I999, p. 50. 


\section{C) Hitstótórica}

ou em suas comunicações com o mundo visível." ${ }^{11}$ Por causa disso, declarou reservar "espírita" e "espiritismo" para a crença que seria apresentada nesta obra. Assim, o programa radiofônico poderia despertar o interesse não apenas de espíritas, mas também de adeptos de outras religiões que compartilhassem a crença na sobrevivência de algo após a morte do corpo, além, é claro, de alcançar os ateus ou agnósticos, porque as ondas hertz, sintonizadas pelos aparelhos de rádio, não pediam credenciais a quem as recebesse.

Alguns anos depois, Geraldo de Aquino e os espíritas organizados em torno da "Hora Espiritualista João Pinto de Souza" demonstram interesse em ampliar seus horizontes na radiodifusão doutrinária. Reformando seus estatutos em I95I, reafirmaram o propósito de divulgação do Espiritismo em seu tríplice aspecto "pela palavra escrita ou falada, através de estações emissoras de rádio desta Capital, enquanto não possuir a sua própria emissora, e, ainda, através de jornais e das tribunas espíritas." ${ }^{52} \mathrm{O}$ arco de possibilidades da propaganda é ampliado: acrescentam, com relação ao primeiro estatuto, a especificidade da palavra escrita no programa de rádio. Certamente muitas apresentações eram lidas no ar. O que fazer com esse material depois? Poderia circular através de jornais espíritas ou leigos e ser apresentado nos Centros Espíritas. Note-se que os programas espíritas de rádio, à semelhança dos demais, são apresentados e divulgados através da imprensa doutrinária e diária. A historiadora Mary Del Priore afirma que "o crescimento da radiodifusão no Brasil foi acompanhado de perto pela imprensa escrita, pois ainda na década de 1930 surgiram algumas publicações especializadas em assuntos radiofônicos" (DEL PRIORE, 20I7, p. 265). A programação das emissoras de rádio era divulgada nos jornais diários. Aqui também, pela primeira vez, vislumbram a possibilidade de terem, para si, uma emissora de rádio. Enquanto não a tivessem, ocupariam os microfones daquelas onde conseguissem espaço para apresentar o programa. Viabilizariam isso promovendo "por todos os meios possíveis e legais, uma campanha com o fim de adquirir ou instalar uma emissora radiofônica, destinada à vasta família espírita do Brasil." 53 Entendiam que diante do crescimento do número de espíritas que fora alcançado até aquele momento e do consequente impacto social que daí decorreria, estariam em condições de iniciar uma campanha junto a estes para terem a própria emissora, adquirindo-a, com a vantagem de já contar com os equipamentos técnicos e a regularização de funcionamento, ou instalando-a, começando do zero.

\footnotetext{
${ }^{51}$ KARDEC, Allan. "Introdução ao estudo da Doutrina Espírita”. O livro dos Espíritos. Rio de Janeiro: FEB, I995, p. I3. 


\section{C) Gitisarórica}

Propunham-se, ainda, "manter um serviço de assistência social que, dentro de suas possibilidades, atenderá a todos os necessitados, indistintamente" 54, serviço que, certamente, canalizaria recursos que poderiam ser destinados ao programa radiofônico, à própria aquisição ou instalação da sonhada emissora de rádio. Pode ser também que os espíritas comprometidos com esse projeto entendessem que seria possível captar recursos da "vasta família espírita do Brasil" para as duas frentes de trabalho a que se propunham. Muitos Centros Espíritas procuravam desenvolver trabalhos de assistência social. Não é por outro motivo que um relatório de Filinto Müller de 1938, sobre as forças religiosas do Brasil, afirmava que "a assistência social mantida pelos espíritas no Rio de Janeiro e no Brasil, além de se traduzir numa grande obra cristã, é alguma coisa de grandioso, dado o alcance de sua benemerência." 55 Por último, tanto no primeiro quanto no segundo estatuto localizado os espíritas envolvidos no empreendimento colocam o Hospital Espírita Obreiros do Bem como beneficiário do patrimônio reunido pelo programa de rádio em caso de sua dissolução. ${ }^{56}$

A "Hora Espírita Radiofônica” “destinada á propaganda e diffusão da doutrina espírita por intermédio do rádio" ${ }^{57}$ foi idealizada, segundo os espíritas da Federação Espírita Brasileira, em "momento de feliz inspiração". Seria, para eles, “desde I do corrente, magnifica realidade, a encher de alegria e esperanças milhares e milhares de almas em todo o Brasil.” 58 Tratava-se uma "promissora iniciativa" que demonstrou êxito em sua inauguração e mobilizou diversas pessoas em todo o país, dada à quantidade de cartas e telegramas que teriam recebido.59 A Liga Espírita do Brasil, através de seu órgão oficial, noticiou a inauguração do programa radiofônico, que "constituiu acontecimento relevante nas atividades espíritas". ${ }^{60}$ A Federação Espírita Brasileira tinha mais instituições a ela vinculadas por todo o Brasil do que a Liga Espírita do Brasil que, por sua vez, contava, na capital do país, com um número maior que ela (OLIVEIRA, 20Io, p. 38).

O programa radiofônico que a Liga Espírita do Brasil conseguiu na Rádio Educadora do Brasil e que foi comandado por Henrique Andrade, em I93I, não teve custos para os espíritas. De acordo com a nota publicada na Revista Espírita do Brasil, a emissora de rádio

\footnotetext{
54 Idem.

55 CPDOC-FGV. Arquivo pessoal Filinto Müller. Serviço de Inquéritos Políticos e Sociais. As forças religiosas no Brasil, do ponto de vista de suas influências políticas e econômicas. Assistência Social. Rio de Janeiro, I938.

${ }^{56}$ Idem e "O Espiritismo pelo rádio". Diário da Noite, op. cit.. O referido hospital chamava-se "Pedro de Alcântara" e foi construído por iniciativa da Associação Espírita Obreiros do Bem. "Nossa história”. Disponível em: https://www.pedrodealcantara.org/nossa-historia Último acesso em 5 de maio de 2020.

57 "Hora Espírita Radiophonica". Correio da Manhã. Rio de Janeiro, 30 de maio de 1939, p. 9.

58 “A “Hora Espírita Radiofônica”". Reformador. Rio de Janeiro, junho de I939, p. I6I.

59 Idem.

60 "Hora Espírita Radiofônica”. Revista Espírita do Brasil. Rio de Janeiro, julho de 1939, p. 472.
} 


\section{C) HitcastórRICA}

"no seu longo programa, no sentido de incentivar os seus princípios educacionais e de fé raciocinada, concedeu á Liga Espírita do Brasil, um quarto de hora nas suas irradiações normaes." ${ }^{\prime}$ De acordo com Lia Azevedo, "na história do rádio brasileiro, o período compreendido entre 1923 e I932 é considerado como experimental" (AZEVEDO, 2002, p. 55). Neste momento do rádio, de pouca variedade na programação das emissoras então existentes e de aparelhos ainda caros para a maioria das pessoas, os espíritas deviam contar com adeptos ou simpatizantes entre os associados da rádio, o que deve ter facilitado a abertura do espaço. Apenas com o Decreto 2I.III, de Io de março de 1932, que regulava os serviços de radiocomunicação no país, colocou-se para as emissoras a necessidade de "aperfeiçoarem" suas instalações, de acordo com as exigências do Governo Federal, o que teriam que realizar dentro de determinado prazo. Deveriam ser exploradas "nas melhores condições que a prática do serviço tiver feito conhecer e mantidas ao nivel dos progressos científicos e técnicos, tendo em vista a maior perfeição e o mais alto rendimento nas radiocomunicações". ${ }^{62}$ Certamente que a obrigação de melhorar instalações e serviços demandaria recursos maiores para as estações de rádio. O Decreto permitiu e regulou, também, a propaganda comercial, o que passaria a gerar rendas adicionais às emissoras, além daquelas que provinham de seus associados (AZEVEDO, 2002, p. 53). Assim, poderiam financiar essa modernização exigida pelo Governo Federal.

As mudanças trazidas pela nova legislação afetaram o programa mantido pela Liga Espírita do Brasil. Em 27 de maio de 1932, a programação da Rádio Educadora do Brasil publicada no jornal $A$ Batalha trouxe a convocação dos sócios quites para uma assembleia geral ordinária que ocorreria em sua sede social. ${ }^{63} \mathrm{Na}$ ordem do dia, eleição da diretoria e para a comissão de finanças. Publicado no início de março e abrindo a possibilidade de exploração comercial dos anúncios, o Decreto 2I.III estimulou tanto os diretores do momento, quanto os que fossem assumir a emissora a quererem levantar recursos a partir das propagandas, já que havia as despesas com a sua modernização. Em carta enviada à Cairbar Schutel, Henrique Andrade afirma que "a direção da Educadora entendeu de não mais permitir que eu falasse gratuitamente, allegando dificuldades." ${ }^{64}$ Acompanhando a programação da emissora verifiquei que o programa foi ao ar em 8 de abril de 1932 e, depois

\footnotetext{
6I "O Espiritismo e o radio". Revista Espírita do Brasil. Rio de Janeiro, novembro de I93I, p. 620.

${ }^{62}$ CÂMARA DOS DEPUTADOS. Decreto 2I.III, de Io de março de 1932. Artigos I5 e 53, "a”. Disponível em: https://www2.camara.leg.br/legin/fed/decret/I930-I939/decreto-2IIII-I-marco-I932-498282-publicacaooriginal8I840-pe.html Último acesso em Io de maio de 2020.

63 "Rádio Educadora do Brasil". A Batalha. Rio de Janeiro, 27 de maio de I932, p. 4.

64 ANDRADE, Henrique. Correspondência de Henrique Andrade a Cairbar Schutel. Rio de Janeiro, Io de maio de 1937. Citado por MONTEIRO, Eduardo Carvalho. História da Radiodifusão Espírita, op. cit.
} 


\section{C) Hitistór RICA}

disso, em 30 de junho, I4 e 2I de julho daquele ano. Henrique Andrade diz que estas transmissões foram "parte de um programa particular" 65 , e tentou pagar o que a rádio exigisse para manter-se no ar, mas que não foi atendido porque a "ordem superior era não fallar"66. Insinua que isso teria ocorrido por influência do clero, mas não desenvolve argumentos para sustentar sua opinião. Não foi por causa disso, porque ainda em I932, a “ordem superior", a direção da emissora, permitiu que quatro programas fossem levados ao ar por Almerindo Martins de Castro entre junho e julho. Em 1933, quem aparece na grade da emissora por três vezes é João Torres, em 3, Io e 24 de agosto daquele ano para realizar palestra sobre "Instrução e educação". ${ }^{67}$ Os dez últimos programas, três levados ao ar por Henrique Andrade, quatro por Almerindo Martins de Castro e três por João Torres foram pagos à emissora. A Revista Espírita do Brasil de janeiro de 1938 menciona, também, que João Torres ocupou os microfones da Rádio Sociedade Mayrink Veiga, mas não informa quando se deu isso. ${ }^{68}$

Outro projeto de divulgação doutrinária requisitou tempo e recursos dos espíritas envolvidos com o programa de rádio e pode ter precipitado o afastamento destes das ondas hertz. Se possuir uma emissora de rádio não estava no horizonte dos espíritas naquele momento, dispor de um jornal diário estava. Para tanto, começam a se organizar em junho de I93I, antes até do programa na rádio, e em 4 de abril de 1932 o jornal Mundo Espírita surge como semanário, não como diário, tendo sido criada a "Empresa Jornalística Mundo Espírita Limitada" com capital de 6:400\$ooo. À frente do empreendimento, Henrique Andrade, João Torres e João de Souza, sendo que os dois primeiros participaram dos programas da Rádio Educadora do Brasil (OLIVEIRA, 2015, p. 93-I07).

Dois fatores se colocam, portanto, para explicar o fim da passagem dos espíritas pelo microfone da Rádio Educadora do Brasil. O Mundo Espírita, que canalizava tempo e recursos dos seus responsáveis e dos espíritas envolvidos com seu projeto editorial, pode ter se tornado prioritário para eles, porque enxergavam no periódico maiores possibilidades na divulgação doutrinária. Além disso, os dirigentes da emissora, diante da mudança da legislação que impunha a exigência de modernizarem instalações e permitia-lhes angariar recursos com propagandas, retomaram o espaço com vistas a conseguirem algo mais vantajoso financeiramente para a manutenção da rádio, ainda mais quando os espíritas

\footnotetext{
65 Idem.

${ }^{66}$ Idem.

${ }_{7}$ "Rádio Educadora do Brasil". A Batalha. Rio de Janeiro, 24 de agosto de 1933, p. 5.

68 "Hora Espírita". Revista Espírita do Brasil, op. cit.
} 


\section{C) GitistóróRICA}

conseguiam levantar recursos para fundarem um jornal. Se podiam organizar-se para fundarem e manterem um jornal, não poderiam fazê-lo para continuar com um programa na rádio?

Os espíritas comprometidos com a "Hora Espiritualista" dispunham da colaboração da Liga Espírita do Brasil para convidar os adeptos da doutrina a participarem de seu financiamento. A Revista Espírita do Brasil, quando anunciou as atividades do programa de rádio em janeiro de 1938 diz que João Pinto de Souza "precisa e deve ser auxiliado não só pelas associações espíritas, em geral, como pelos nossos confrades commerciantes e industriaes, dando-lhes annuncios de suas casas e especialidades." ${ }^{69}$ Contavam, assim, com o auxílio financeiro dos Centros Espíritas e com anúncios comerciais. No livro de registro de médiuns do Grupo de Caridade Deus, Luz e Amor constavam "muitas pessoas ligadas ao comércio (descritos como "comerciários", "comerciantes" ou, simplesmente, "comércio")" (OLIVEIRA, 20IO, p. 20). Embora não se possa generalizar, é possível supor que, nas regiões mais abastadas da cidade, os Centros Espíritas contassem com frequentadores e dirigentes com melhor situação financeira. Rememorando a fundação da "Hora Espiritualista" e exaltando os esforços de João Pinto de Souza, a Revista Espírita do Brasil um ano depois de sua fundação afirma que "auxílio material, não tendo obtido de entidades espíritas, absorvidas em outros negócios, o Pinto conseguiu em annuncios de casas commerciais de confrades nossos".70 A ajuda dos Centros tardou, porque estes tinham outras prioridades. Isso incomodou àqueles que julgavam que o mais acertado para o momento era cerrar esforços em torno da propaganda pelo rádio. Lins de Vasconcellos, quando estava à frente do Mundo Espírita também fez queixa parecida no que diz respeito à imprensa. Em 1949, onze anos depois, reclama que os "Centros poderiam fazer muito, mas as preocupações com o mediunismo e assistência social, o amparo aos pobres, absorvem tudo, levando muitos a não tratarem com a devida atenção a propaganda sistemática da Doutrina."71 Aliás, vários periódicos espíritas utilizaram-se de anúncios comerciais para subsidiarem suas atividades de divulgação, inclusive os órgãos oficiais das duas federativas (OLIVEIRA, 2015, p. II7-I2I).

A diretoria do Grupo de Caridade Deus, Luz e Amor informou, em 1939, ter recebido uma carta da "Hora Espiritualista" "pedindo um auxílio para a continuação da sua

\footnotetext{
69 "Hora Espírita". Revista Espírita do Brasil, op. cit.

70 "Hora Espiritualista". Revista Espírita do Brasil. Rio de Janeiro, agosto de I938, p. I85.

${ }^{71}$ LOPES, Arthur Lins de Vasconcellos. “Imprensa Espírita”. Mundo Espírita. Rio de Janeiro, I6 de julho de I949, capa.
} 


\section{C) HitcastórRICA}

transmissão - Responder, auxiliando com a contribuição mensal de cinco mil réis". ${ }^{72}$ Como era um Centro Espírita adeso à Liga Espírita do Brasil, é possível que o "Livro de Registro das Associações Agregadas à Liga Espírita do Brasil" tenha sido usado para conseguirem o endereço desta e de outras instituições a ela filiadas. Assim como este, outros Centros Espíritas devem ter contribuído, ainda que esporadicamente. Só que essa ajuda financeira não chegou nos primeiros tempos do programa e as despesas eram urgentes e apertavam, afinal "as emprezas de Rádio não vivem a dar horas, mas vivem do que lhes dão as horas, ou então não vivem."73 Os espíritas envolvidos com a "Hora Espiritualista" alegavam que, se recebessem auxílio financeiro para sua manutenção ela progrediria e poderia "diminuir os annuncios, augmentando o tempo dos oradores". ${ }^{74}$ Diminuiria a dependência dos anunciantes com ganho para a divulgação doutrinária. Em 1939, quando dão personalidade jurídica ao programa registrando seus estatutos, formalizam o seu financiamento para efeitos legais, que consistira também em "mensalidades de cooperadores, doações quaisquer e rendas diversas,"75 embora não especificadas nesta publicação.

A estratégia de dar segurança legal através da constituição de personalidade jurídica foi adotada primeiro pelos responsáveis da "Hora Espírita Radiofônica”. Leopoldo Machado escreve ao Diário da Noite que publicara os extratos dos estatutos da "Hora Espiritualista" como se fossem os do programa que ele estava à frente. Segundo ele, "já estava legalmente constituída em sociedade, com personalidade jurídica, antes mesmo de sua inauguração". ${ }^{76}$ A comissão responsável pelo programa "endereçou circular a todas as agremiações espíritas e a todos os confrades do seu conhecimento, dando-lhes ciência do facto que noticiamos e convidando-os a se fazerem cooperadores da "Hora Espírita Radiofônica"”, 77 mesma estratégia utilizada pelo programa comandado por João Pinto de Souza, quem sabe também usando os registros de Centros Espíritas da própria Federação Espírita Brasileira. Quem não recebesse a correspondência e quisesse tornar-se cooperador, deveria procurar o secretário Victor Torquato de Souza na sede da federativa. O secretário, aliás, participava do Centro Espírita de Jacarepaguá, que na reunião de diretoria realizada em 7 de julho de 1939 leu a

${ }^{72}$ GRUPO DE CARIDADE DEUS, LUZ E AMOR. Sessão Ordinária da Directoria. Rio de Janeiro, I2 de outubro de 1939, p. 24.

73 "Hora Espírita”. Revista Espírita do Brasil, op. cit.

74 Idem.

75 “O Espiritismo pelo rádio”. Diário da Noite, op. cit..

76 “A Hora Espiritualista não é a Hora Espírita Radiofônica”. Diário da Noite. Rio de Janeiro, I4 de agosto de I939, p. 5.

77 “Hora Espírita Radiofônica”. Reformador. Rio de Janeiro, maio de 1939, p. I52. 


\section{C) GitistóróRICA}

circular e deliberou contribuir com “a importância da quota mensal de Io\$ooo." 78 Luiz Olímpio Guillon Ribeiro, no relatório de atividades da Federação Espírita Brasileira apresentado em setembro de 1939, afirma que o "numero, crescente sempre, dos que se alistam como seus cooperadores, por meio de contribuições mensais, que vão desde as de I\$ooo até ás de centenas de mil réis."79 Os espíritas comprometidos com a "Hora Espírita Radiofônica” estavam confiantes em receber o amparo dos seus confrades e, por isso, avisaram que não haveria espaço para anúncios comerciais. Além disso, tinham no horizonte a possibilidade de tornarem o programa diário. ${ }^{80} \mathrm{~A}$ confiança justificava-se naquele momento. Contavam com os recursos da Federação Espírita Brasileira, que dava "á instituição da Hora Espirita Radiofonica decidido apoio, assim moral, como de natureza material, apoio que continua a dispensar-lhe." ${ }^{8 I}$ Recebiam, também, doações anônimas. Em 22 de junho de 1939, o Diário da Noite relatou a visita de um homem desconhecido à sua redação. Este teria deixado um envelope com o nome do jornal. Dentro dele, um bilhete ao redator e uma outra carta fechada, endereçada ao tesoureiro da "Hora Espírita Radiofônica". No bilhete, o desejo de manter o anonimato. No outro envelope, uma carta de um suposto rico que demonstrava admiração pelos trabalhos assistenciais dos espíritas e que relatava um vazio existencial em sua vida endinheirada até que conheceu a Doutrina Espírita. Além da carta, um cheque de dez contos de réis.

Bendicto sejam todos os que, pelo radio, vêm agora trazer-nos a comprehensão da vida e levar aos ouvidos dos desgraçados, como eu me sentia, essa fortuna evangélica que procurei vinte e seis annos e que agora é apresentada pela voz divina e se ouve pelo radio, ensinando-nos de onde viemos, o que somos e para onde nos dirigimos. ${ }^{82}$

Outro recurso que os dirigentes do programa utilizaram para levantar fundos foi a venda de folhetos das apresentações realizadas através das ondas hertz. Diziam que isso atenderia a demanda de simpatizantes, alguns dos quais colaboradores financeiros que, das irradiações dos programas "não podem, por circunstâncias diversas, aprecia-las, nem delas

${ }^{78}$ CENTRO ESPÍRITA DE JACAREPAGUÁ. Reunião ordinária de diretoria. Rio de Janeiro, 7 de julho de 1939, p. 57.

${ }^{79}$ RIBEIRO, Luiz Olímpio Guillon. "Relatório apresentado, pelo seu presidente, à Assembléia Deliberativa, na reunião ordinária de 1939, sôbre os trabalhos da instituição e a gestão do seu patrimônio moral e material, durante o ano social de I de Julho de 1938 a 30 de Junho de 1939". Reformador, op. cit., p. 302.

80 "Hora Espírita Radiofônica". Reformador. Rio de Janeiro, maio de I939, p. I5I e I52.

${ }^{81}$ RIBEIRO, Luiz Olímpio Guillon. "Relatório apresentado, pelo seu presidente, à Assembléia Deliberativa, na reunião ordinária de 1939, sôbre os trabalhos da instituição e a gestão do seu patrimônio moral e material, durante o ano social de I de Julho de 1938 a 30 de Junho de I939". Reformador, op. cit, p. 302.

82 "Cheque de dez contos para a Hora...". Diário da Noite. Rio de Janeiro, 22 de junho de I939, última edição, p. 4. 


\section{C) HitcastórRICA}

tirar qualquer proveito." 83 Os que solicitavam a publicação dos folhetos alegavam que, dada a importância do material irradiado através dos programas, ele não poderia ficar sepultado nos arquivos da "Hora Espírita Radiofônica", uma vez que se tratava de "tanta coisa instrutiva e elucidativa de muitos dos assuntos capitais da Doutrina Espírita." ${ }^{4}$ Além disso, alegavam limitações técnicas, por "não serem uniformemente ouvidas todas as irradiações, devido á variabilidade das condições atmosféricas, á deficiencia dos aparelhos receptores e, mesmo, á potencialidade da estação, que não dá para que chegue a todos os lugares, nitidamente, o que é por ela irradiado." 85 Por último, questões ligadas ao tempo disponível, por "não poderem muitos a quem elas interessam ouvi-las, pela hora em que são feitas, isto é, quando esses interessados ainda se encontram no trabalho, ou em viagem para casa." ${ }^{86}$ A impressão dos folhetos também poderia atender àqueles que não tivessem aparelhos de rádio e os que, no horário do programa, tivessem outro compromisso, como uma reunião no Centro Espírita. A demanda pelos folhetos seria, para eles, indicador do êxito alcançado pelo programa, "exito que comprova haver a sua creação correspondido ao anhelo com que uma porção imensa de Brasileiros se volta para o Espiritismo". ${ }^{87}$

A venda de folhetos com textos utilizados nos programas de rádio também financiou outras frentes de trabalho dos espíritas. Em novembro de 1933, na Revista Espírita do Brasil, lemos que as palestras de João Torres, em número de cinco, foram transformadas em folhetos e vendidas na sede da entidade federativa, nas de alguns Centros (não menciona quais) e na Rua do Ouvidor "pelo nosso irmão cego Barnabé, vendedor ambulante" 88 . Consegui localizar três programas apenas com o nome de João Torres em 1933. As outras duas participações podem ter se dado entre o final de I93I e 1932, quando Henrique Andrade ainda estava à frente. $\mathrm{O}$ produto das vendas seria revertido não para a rádio, ou para a sustentação material do programa, mas sim para a Sociedade Escolar Espírita, ligada à entidade federativa e que mantinha as Escolas “Allan Kardec" e "Bezerra de Menezes".

A atuação de alguns espíritas na radiofonia não aparece nas histórias do rádio no Brasil, apenas nas memórias produzidas por seus adeptos. Os seguidores da doutrina organizada por Allan Kardec abrem espaço nas emissoras de rádio numa década de grandes transformações para esse veículo de comunicação, em que este ainda encontrava-se em

\footnotetext{
83 “Hora Espírita Radiofônica”. Reformador. Rio de Janeiro, agosto de 1939, p. 246.

84 Idem.

85 Idem.

${ }^{86}$ Idem.

${ }^{87}$ Idem.

88 "Palestras pela rádio educadora". Revista Espírita do Brasil. Rio de Janeiro, novembro de 1933, p. 196.
} 


\section{C) HitcastórRICA}

processo de desenvolvimento técnico e profissional, sendo normatizado, pelos instrumentos legais na medida em que se expandia. Embora muitas vezes encabeçadas por um indivíduo, o iniciador ou entusiasta do empreendimento, as ações dos espíritas no rádio contavam com uma rede de apoios material e moral entre aqueles que possuíam visões em comum sobre o Espiritismo. Esses grupos colaboravam na organização dos programas radiofônicos, seja emprestando seus conhecimentos doutrinários, seja participando dos seus bastidores, dedicando-se às tarefas administrativas. Além disso, cerravam esforços em torno do financiamento dessas atividades radiofônicas, acionando adeptos e suas instituições. Apesar de mais estreitamente vinculados a determinadas instituições de natureza federativa, isso muitas vezes não os impedia de colaborarem em outros programas que contavam com quadros mais identificados com outras instituições. Os microfones das rádios foram ocupados por pessoas que já desenvolviam trabalho de divulgação do Espiritismo através da palavra falada nas palestras doutrinárias e da palavra escrita na imprensa doutrinária, em seus próprios periódicos ou nas colunas dos jornais diários da cidade. Os registros da participação dos adeptos do Espiritismo no rádio encontram-se em maior número nos jornais doutrinários, onde anunciam seus programas radiofônicos, aprofundavam questões relacionadas às expectativas que possuíam com o uso da radiofonia e repercutem os clamores por auxílio financeiro. Nos jornais diários, fazem-se presentes quase sempre nas colunas mantidas por espíritas e nas programações das rádios. O investimento na radiofonia denota, por parte dos adeptos do Espiritismo, o reconhecimento de que a utilização deste meio de comunicação potencializaria a divulgação doutrinária, o que levaria ao aumento do número de adeptos e o consequente reforço na legitimação social de suas práticas e estudos doutrinários.

\section{Referências Bibliográficas:}

AZEVEDO, Lia Calabre. No tempo do rádio. Radiodifusão e cotidiano no Brasil. 1923 - 1960. Tese de Doutoramento em História. UFF. Niterói, 2002.

COELHO, Patrícia. "Os pioneiros do rádio e os desafios da regulamentação da radiodifusão no Brasil dos anos 1920". Revista Brasileira de História da Mídia (RBHM) - v.3, n.I, jan.20I4jun/20I4.

DEL PRIORE, Mary. Histórias da gente brasileira, Volume 3: República - Memórias (I889-1950). Rio de Janeiro: LeYa, 20I7. 


\section{C) HitcastórRICA}

OLIVEIRA, Marco Aurélio Gomes de. Imprensa Espírita na cidade do Rio de Janeiro: Propaganda, Doutrina e Jornalismo (I880-I950). Rio de Janeiro: Autografia, 2015.

OLIVEIRA, Marco Aurélio Gomes de. "Livres", porém perseguidos: O cotidiano das relações entre espíritas e a Polícia na cidade do Rio de Janeiro (I930-1950). Monografia de Conclusão do Curso de Graduação em História. UFF, Niterói, 2010.

Recebido: 14 de julho de 2020

Aprovado: 23 de setembro de 2020 